\title{
AN UNUSUAL CAUSE OF VENTILATOR LEAK
}

\section{STEPHEN ROLBIN}

THE OBjective of THIS PAPER is to present an unusual cause of ventilator leak that has been detected twice in a period of one year in our institution. It is well known to every anaesthetist that the use of an automatic ventilator introduces a new set

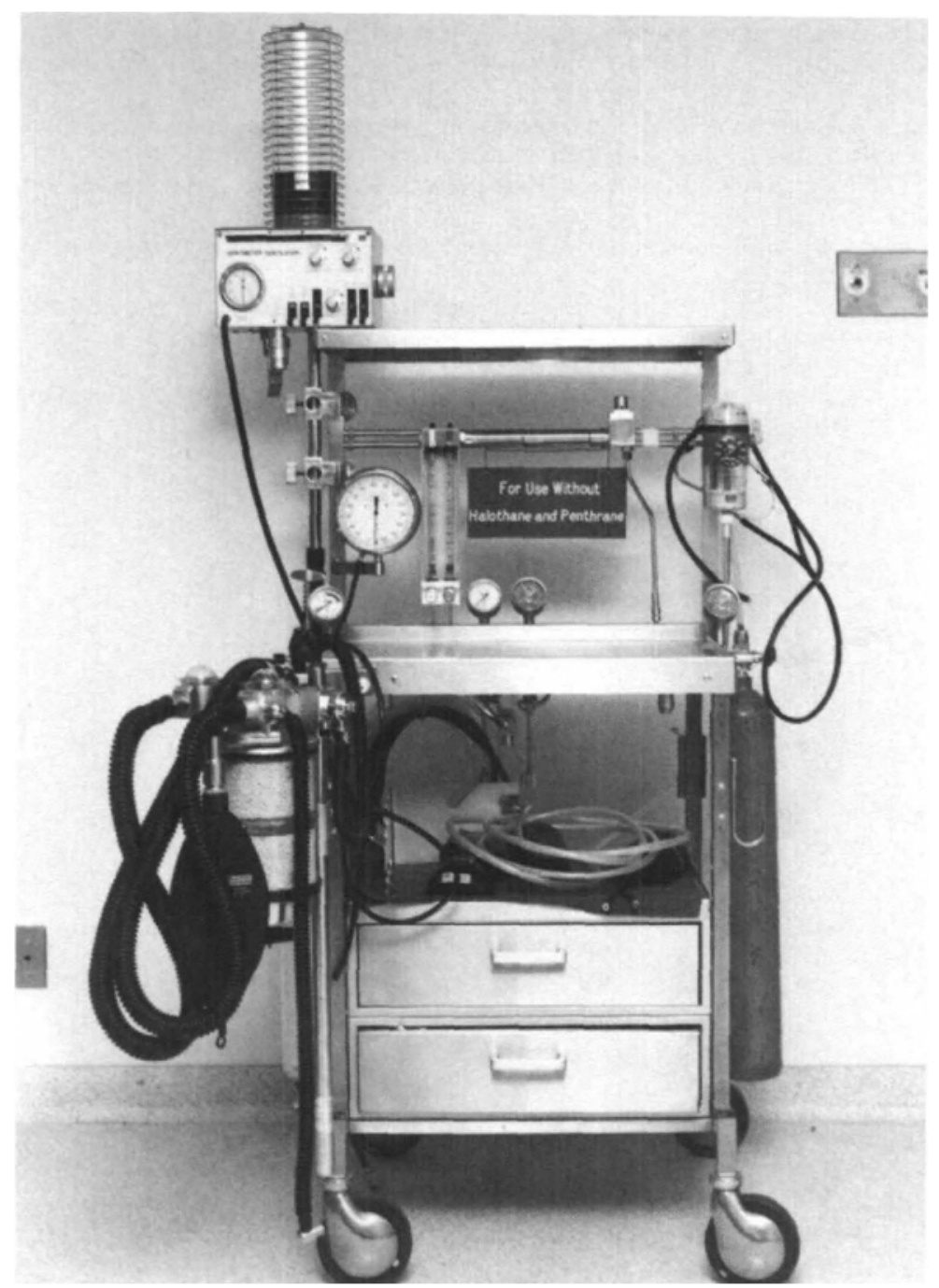

Figure 1. View of mounting of ventilator to the anaesthetic machine.

Stephen Rolbin, M.D., F.R.C.P.(C), Department of Anaesthesia, Mount Sinai Hospital, 600 University Avenue, Toronto M5C 1 X5.

Canad. Anaesth. Soc. J., vol. 24, no. 4, July 1977 


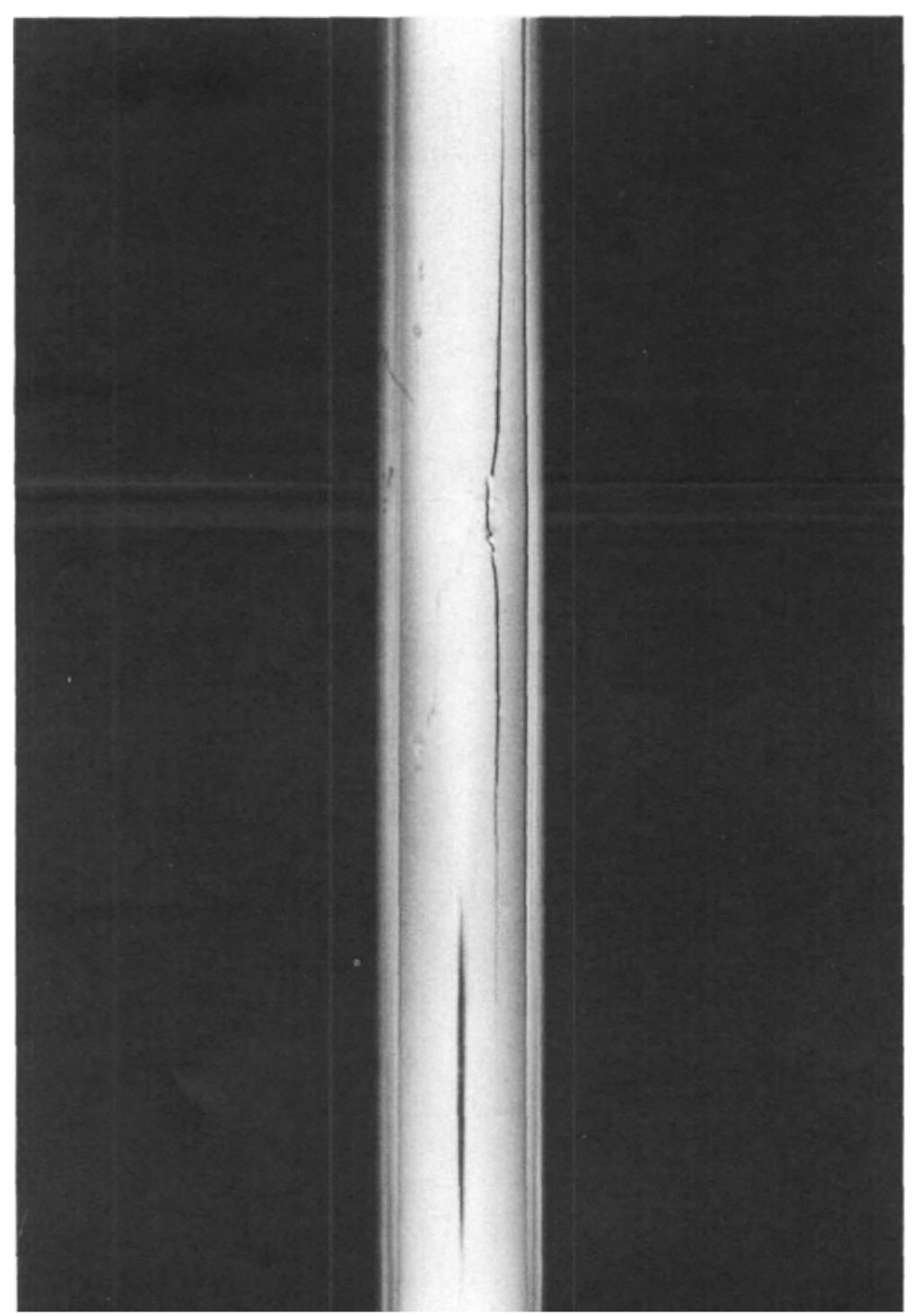

Figune 2. The damaged connecting pipe.

of risks for the patient. ${ }^{1} \mathrm{~A}$ false sense of security is easily generated by the constant noise the machine makes. The anaesthetist needs to be on continued alert for mechanical failure.

In a recent review Dorsch and Dorsch ${ }^{2}$ enumerated several common locations of leaks such as the "vaporizer, filler caps, cracks in the flowmeter tubes, connections of the flowmeter tubes, empty yokes and connections on the back of the machine." In our particular case it was noted that there was a slow leak in the machine. This could be compensated for by using a flow rate of 6 liters per minute of nitrous oxide and 4 liters per minute of oxygen instead of flow rates of 4 and 2 
liters per minute used by the author. Careful checking failed to reveal any leak in the circle system, absorber, or the anaesthetic machine. The Air Shields Ventimeter Ventilator which was used was changed but the problem persisted and the volume of leakage increased over the following hour until the patient could no longer be adequately ventilated.

Figure 1 illustrates the type of anaesthetic machine and ventilator used. Note that there is a vertical metal bar running from the Ventimeter Ventilator to a rubber connecting tube and that it is held in place by two clamps. Figure 2 illustrates the cracks as they appeared in this vertical pipe at the site of application of the clamps.

Most anaesthetists familiar with this ventilator and encountering a similar problem would suspect a leak in the rubber tubing or in the ventilator bellows. To my knowledge a leak in the metal pipe which is supplied with the ventilator has never been described. The unusual site of the leak would make it harder to detect and to correct quickly. Since this particular defect has been detected twice in the period of one year in our institution, it was felt that knowledge of this potential problem would benefit all anaesthetists who use the Air Shields Ventilator.

\section{SUMMARY}

This paper describes an unusual site of leakage in the Air Shields Ventilator.

\section{RÉSUMÉ}

Le ventilateur Air Shield est fixé à l'appareil anesthésique à l'aide d'un crampon reliant le conduit d'arrivée des gaz frais du ventilateur au cadre metallique de l'appareil anesthesique.

L'auteur rapporte deux cas où un bris de ce tuyau a été constaté à l'endroit précis où le crampon fixe le ventilateur à la machine anesthésique. Dans les deux cas, le bris etait assez important pour occasionner une fuite. L'auteur souligne le fait qu'à moins d’avoir cette possibilité présente a l'esprit, l'anesthésiste éprouvera des difficultés à localiser la fuite.

\section{REFERENCES}

1. Mushin, Rendell-Baker, Thompson, Mapelson Automatic ventilation of the lungs, 2nd ed., Blackwell Scientific Foundations (1969).

2. Dorsch, J.A. \& Dorsch, S.E. 1976 Annual Refresher Course Lectures, Lecture 134. 